\title{
MORPHOMETRIC ANALYSIS OF LUMBAR VERTEBRAE AND ITS APPLIED CLINICAL IMPORTANCE
}

\section{Suranjana Banik *1, Ajita Rajkumari ${ }^{2}$.}

${ }^{* 1}$ Post Graduate Trainee in MD Anatomy, Department of Anatomy, Regional Institute of Medical Sciences, Imphal, Manipur India.

${ }^{2}$ Professor, Department of Anatomy, Regional Institute of Medical Sciences, Imphal, Manipur India.

\section{ABSTRACT}

Introduction: The lumbosacral spine is the region of transition from the appendicular to the axial skeleton. Accidents, degenerative conditions, congenital defects and neoplastic metastases often affect the lumbar region. Low back pain resulting from lumbar canal stenosis is one of the major complaints in young to adult population. Apart from that lumbar vertebrae morphometry is required in many surgical as well as anaesthetic procedures. Aims and objectives: The present study was undertaken to determine the morphometry of human cadaveric lumbar vertebrae and to compare findings with other authors and forming a baseline data in relation to various lumbar canal pathologies that can be of help to the medical and surgical experts.

Materials and methods: Dried lumbar vertebrae were obtained from the Department of Anatomy of Regional Institute of Medical Sciences, Imphal, India. Vertebrae belonging to same set and without any external deformity were chosen and separated into typical and atypical ones. Measurement of Midsaggital diameter, Interpedicular distance, and Anteroposterior diameter of lateral recess was done using digital vernier calliper.

Observations and Results: The study showed increase in all the diameters from L1 to L5 with a narrowing in all cases at L3 level. Therefore, L3 remains the transition point in all the measurements and thus one of the possible sites for nerve root compression due to canal stenosis, which is one of the major causes of low back pain.

Conclusion: The present data forms a baseline of adult lumbar vertebral morphology and is useful source of information to surgeons, physicians and anatomists. It is also helpful for the screw and implant manufacturers. Further study with sex and ethnic consideration can generate forensic and anthropological data.

KEY WORDS: Lumbar vertebrae, Lumbar canal stenosis, Morphometry, Midsaggital diameter, Interpedicular distance, Lateral recess diameter.

Address for Correspondence: Dr. Suranjana Banik, Regional Institute of Medical Sciences, Department of Anatomy, Lamphelpat, Imphal, Manipur-795004; Imphal, India.

Mobile: +917005344990 E-Mail: suranjanabanik@gmail.com

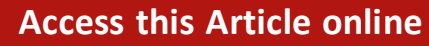

Quick Response code

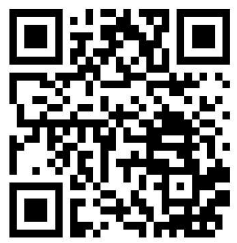

DOI: $10.16965 /$ ijar.2019.122

Journal Information

International Journal of Anatomy and Research

ICV for 2016
90.30
ISSN (E) 2321-4287 | ISSN (P) 2321-8967

https://www.ijmhr.org/ijar.htm DOI-Prefix: https://dx.doi.org/10.16965/ijar

\section{Article Information}

Received: 25 Jan 2019

Peer Review: 28 Jan 2019

Revised: None
Accepted: 07 Mar 2019

Published (O): 05 Apr 2019

Published (P): 05 Apr 2019

\section{INTRODUCTION}

The lumbosacral spine is the region of transition from the appendicular to the axial skeleton. When we walk, there is significant biomechanical load placed across the lumbar towards sacral junction. Usually the lordotic lumbar spine consists of five non-rib bearing, mobile bony segments between the rigid thoracic and fused sacral vertebrae, which act as a conduit for the cauda equina [1]. Lumbar vertebrae are unique in their large size, absence of costal facets and transverse foramina and wide body. Pedicles are 
short, spinous process almost horizontal, thickened and quadrangular. The transverse process of fifth lumbar vertebra is massive and the body is usually the largest and markedly deeper anteriorly, contributing to the lumbosacral angle [2].

Accidents, degenerative conditions, congenital defects and neoplastic metastases often affect the lumbar region. Around $75 \%$ of patient complaint of low-back pain and some show progressed presentations like herniated disc in around $3-5 \%$ cases while $1-2 \%$ is found to have compression of nerve root [3]. One of the reasons of compression is the unyielding bony nature, which is liable to abnormal stenosis or narrowing [4]. Spinal stenosis can be classified as: (i) central, when it affects the spinal canal; (ii) foraminal, when it affects the intervertebral foramen (iii) lateral, when it affects the lateral recesses [5].

Garfin et al and Ciricillo SF et al stated that apart from being a common finding in patients over 55 years of age, vertebral canal stenosis maybe a finding in newborns indicating its congenital origin too[6,7]. The acquired spinal stenosis occurs mainly due to age related degeneration of the intervertebral disc and ligamentum flavum. Mild symptoms may be managed by multimodality treatment whereas severe symptoms need decompression surgery. In recent days, nonfusion stabilization of the lumbar spine has become a popular treatment modality because of its less or no negative effects on the adjacent segments and also excellent restoration of inter-segmental motion to the magnitude of the intact spine [8]. The surgical intervention and instrumentation requires thorough knowledge of the anatomy of the lumbar region $[9,10]$.

In Neurosurgery, technique like anterior access to L1-L5 vertebrae for lesion excision, corpectomy, vertebral body reconstructions with cages, realignment, plating and screwing etc require adequate morphometric knowledge about the body of lumbar vertebrae and the discs and standard volumetric data [11]. For the morphometry of lumbar vertebra, certain diameters are important and studies show that measurement of the interpedicular distance, the mid-sagittal diameter and the antero-posterior diameter of the lateral recess may be a preliminary but informative data in the diagnosis of lumbar spinal canal stenosis [12].

The aim of the study is to study the morphometry of the lumbar vertebrae and comparing it with findings available and forming baseline data that can guide the surgeons and clinicians in their diagnosis and treatment.

\section{MATERIALS AND METHODS}

Fig. 1: Diagrammatic representation of the three measurements taken

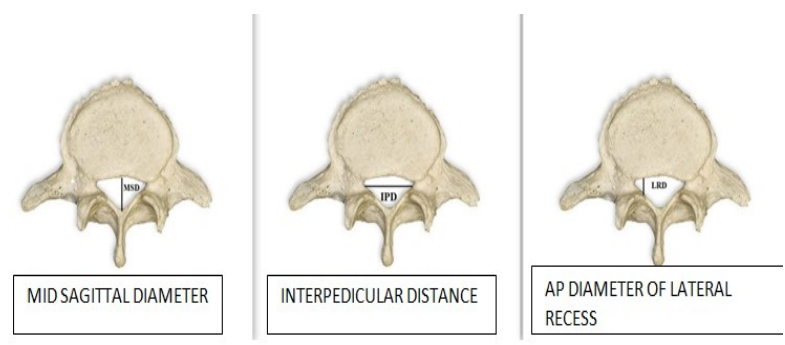

Fig. 2: Measurement of various diameters using digital vernier calliper.
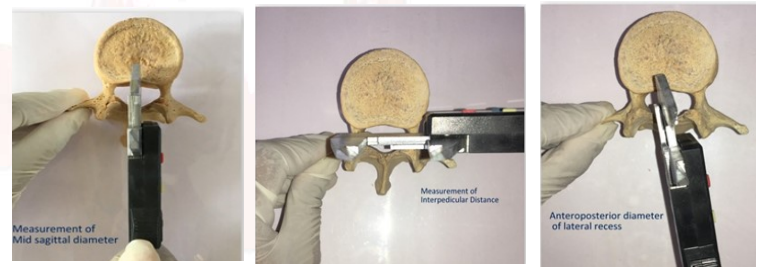

This was a cross sectional study done in the Department of Anatomy of Regional Institute of Medical Sciences, Imphal, India. 10 sets i.e. 50 dried normal and fully ossified cadaveric lumbar vertebrae were studied. Deformed And broken vertebrae were excluded. Sex, age and ethnicity was not considered. Typical vertebrae L2-L4 and L1, L5 were separated.

\section{Following measurements were recorded}

1. Midsaggital diameter.

2. Interpedicular distance.

3. Anteroposterior diameter of lateral recess.

The interpedicular distance was measured as the distance between the inner borders of both the pedicles while the midsagittal diameter was measured as the distance between the lamina posteriorly at the midline and posterior border of body of the vertebra. The anteroposterior diameter of lateral recess (depth) is measured from the dorsal surface of the vertebral body to the most ventral segment of the superior articular facet (fig 1) [12].

The measurements were done (fig 2) using a 
Suranjana Banik, Ajita Rajkumari. MORPHOMETRIC ANALYSIS OF LUMBAR VERTEBRAE AND ITS APPLIED CLINICAL IMPORTANCE.

digital vernier calliper (Precision $0.01 \mathrm{~mm}$ ). Three readings were taken for each measurements and mean of these was obtained to exclude the personal error. All measurements were recorded in $\mathrm{mm}$.

Data were collected, revised and analyzed by using SPSS statistical package version 21.

\section{The following analysis has been made:}

Descriptive statistics: For quantitative data we used: Mean and standard deviation.

For qualitative data: number ( $\mathrm{n}$ ) and percentage (\%)

\section{RESULTS}

Table 1: Measurement of midsagittal diameter, interpedicular distance, anteroposterior diameter of lateral recess of lumbar vertebral canal at L1-L5 level.

\begin{tabular}{|c|c|c|c|}
\hline $\begin{array}{l}\text { Vertebral } \\
\text { Level }\end{array}$ & $\begin{array}{c}\text { Sagittal diameter of } \\
\text { Vertebral canal in } \mathrm{mm}\end{array}$ & $\begin{array}{l}\text { Interpedicular } \\
\text { Distance in } \mathrm{mm}\end{array}$ & \begin{tabular}{|c|} 
Anteroposterior \\
Diameter of lateral \\
Recess in $\mathrm{mm}$ \\
\end{tabular} \\
\hline \multirow{10}{*}{$\mathrm{L}_{1}$} & 13.35 & 19.88 & 9.62 \\
\hline & 13.58 & 19.52 & 9.85 \\
\hline & 12.02 & 22.59 & 9.76 \\
\hline & 13.01 & 16.22 & 8.96 \\
\hline & 13.67 & 20.82 & 8.68 \\
\hline & 14.79 & 22.09 & 7.82 \\
\hline & 11.22 & 19.07 & 7.34 \\
\hline & 14.6 & 21.63 & 7.61 \\
\hline & 12.43 & 21.05 & 8.95 \\
\hline & 12.4 & 19.6 & 8.78 \\
\hline \multirow{10}{*}{$\mathrm{L}_{2}$} & 13.98 & 21.58 & 9.24 \\
\hline & 15.34 & 21.97 & 8.43 \\
\hline & 14.2 & 22.19 & 10.02 \\
\hline & 12.94 & 18.59 & 9.14 \\
\hline & 12.83 & 19.87 & 9.97 \\
\hline & 13.7 & 21.43 & 10.77 \\
\hline & 15.7 & 19.57 & 9.34 \\
\hline & 16.18 & 22.14 & 9.59 \\
\hline & 14.86 & 21.76 & 10.36 \\
\hline & 13.6 & 21.5 & 9.76 \\
\hline \multirow{10}{*}{$\mathrm{L}_{3}$} & 12.68 & 20.57 & 8.25 \\
\hline & 14.26 & 21.07 & 9.14 \\
\hline & 12.6 & 22.78 & 8.75 \\
\hline & 11.11 & 23.71 & 9.04 \\
\hline & 13.83 & 19.98 & 10.86 \\
\hline & 13.39 & 20.05 & 10.03 \\
\hline & 14.4 & 19.97 & 8.16 \\
\hline & 14.79 & 21.7 & 8.81 \\
\hline & 11.45 & 19.41 & 10.02 \\
\hline & 14.35 & 19.5 & 8.5 \\
\hline \multirow{10}{*}{$\mathrm{L}_{4}$} & 11.17 & 19.53 & 10.2 \\
\hline & 15.8 & 20.98 & 10.6 \\
\hline & 12.67 & 24.28 & 9.16 \\
\hline & 12.7 & 23.18 & 9.15 \\
\hline & 13.36 & 21.39 & 10.84 \\
\hline & 12.03 & 24.94 & 9.97 \\
\hline & 14.68 & 20.98 & 9.4 \\
\hline & 12.15 & 20.65 & 8.99 \\
\hline & 13.57 & 22.4 & 10.65 \\
\hline & 15.75 & 20.5 & 8.5 \\
\hline \multirow{10}{*}{$L_{5}$} & 14.54 & 24.35 & 9.88 \\
\hline & 15.5 & 23.66 & 9.7 \\
\hline & 13.07 & 23.45 & 9.65 \\
\hline & 16.83 & 23.61 & 9.78 \\
\hline & 13.93 & 24.56 & 9.49 \\
\hline & 14.65 & 25.83 & 9.52 \\
\hline & 14.34 & 25.97 & 9.9 \\
\hline & 15.58 & 24.53 & 9.8 \\
\hline & 12.58 & 25.36 & 9.99 \\
\hline & 16.75 & 25.75 & 9.8 \\
\hline
\end{tabular}

Mean Mid Sagittal diameter at L1,L5 level was $13.10 \pm 1.124-14.77 \pm 1.414 \mathrm{~mm}$, at L2 level was $14.33 \pm 1.147 \mathrm{~mm}$, at L3 level was $13.28 \pm$ $1.283 \mathrm{~mm}$ and at L4 level was $13.38 \pm 1.577 \mathrm{~mm}$ (Table1, 2 ); (Figure 3). Interpedicular distance at L1,L5 level was $20.24 \pm 1.839-24.70 \pm 0.967$ $\mathrm{mm}$, at L2 level was $21.06 \pm 1.251 \mathrm{~mm}$, at L3 level was $20.87 \pm 1.445 \mathrm{~mm}$ and at $L 4$ was 21.88 $\pm 1.760 \mathrm{~mm}$ (Table1, 3; Figure 4). Anteroposterior diameter at lateral recess was $8.73 \pm 0.896$ $\mathrm{mm}-9.75 \pm 0.161 \mathrm{~mm}$ at L1, L5 level , at L2 was $9.66 \pm 0.668 \mathrm{~mm}$, at $\mathrm{L} 3$ was $9.15 \pm 0.879 \mathrm{~mm}$ and at L4 was $9.74 \pm 0.161 \mathrm{~mm}$ (Table 1, 4: Figure 5)

There has been increase in average Mid Sagittal diameter, Interpedicular distance and Anteroposterior diameter at lateral recess from $\mathrm{L} 1$ to L5 except at L3.

There has been reduction in all diameters at L3 level and so it may be inferred that $L 3$ remains the center point for transition in the diameters and hence more susceptible to stenosis and spinal nerve compression.

Table 2: mean mid sagittal diameter at level L1- L5.

\begin{tabular}{|c|c|c|}
\hline Vertebral level & $\begin{array}{c}\text { Mean of mid sagittal } \\
\text { diameter }(\mathrm{mm})\end{array}$ & $\begin{array}{c}\text { Standard } \\
\text { deviation }\end{array}$ \\
\hline L1 & 13.1 & 1.124 \\
\hline L2 & 14.33 & 1.147 \\
\hline L3 & 13.28 & 1.283 \\
\hline L4 & 13.38 & 1.577 \\
\hline L5 & 14.77 & 1.414 \\
\hline
\end{tabular}

Table 3: Measurement of inter-pedicular distance at level L1- L5.

\begin{tabular}{|c|c|c|}
\hline Vertebral level & $\begin{array}{c}\text { Mean of } \\
\text { interpedicular } \\
\text { distance (mm) }\end{array}$ & $\begin{array}{c}\text { Standard } \\
\text { deviation }\end{array}$ \\
\hline L1 & 20.24 & 1.839 \\
\hline L2 & 21.06 & 1.251 \\
\hline L3 & 20.87 & 1.445 \\
\hline L4 & 21.88 & 1.76 \\
\hline L5 & 24.7 & 0.967 \\
\hline
\end{tabular}

Table 4: Measurement of anteroposterior diameter of lateral recess at level L1-L5.

\begin{tabular}{|c|c|c|}
\hline Vertebral level & $\begin{array}{c}\text { Mean of ap diameter } \\
\text { of lateral recess }(\mathrm{mm})\end{array}$ & $\begin{array}{c}\text { Standard } \\
\text { deviation }\end{array}$ \\
\hline L1 & 8.73 & 0.896 \\
\hline L2 & 9.66 & 0.668 \\
\hline L3 & 9.15 & 0.879 \\
\hline L4 & 9.74 & 0.812 \\
\hline L5 & 9.75 & 0.161 \\
\hline
\end{tabular}


Fig. 3: chart showing distribution of mid sagittal diameter at level L1-L5.

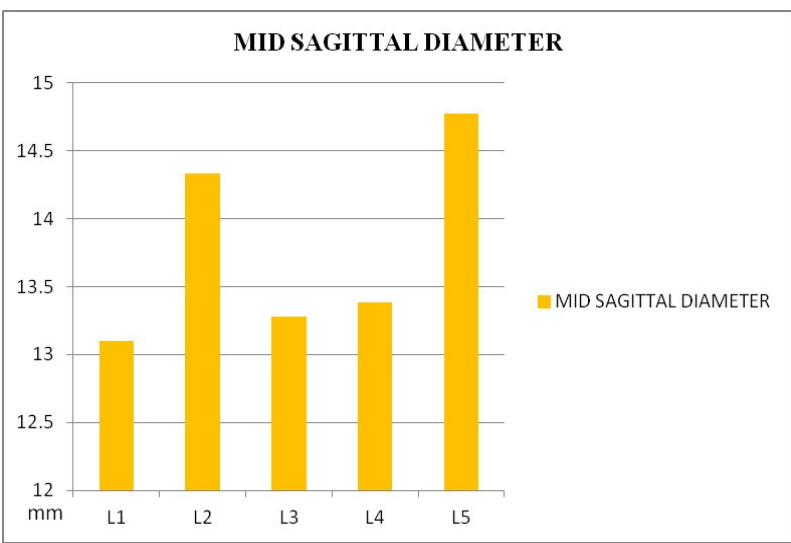

Fig. 4: chart showing distribution of interpedicular distance at level L1-L5.

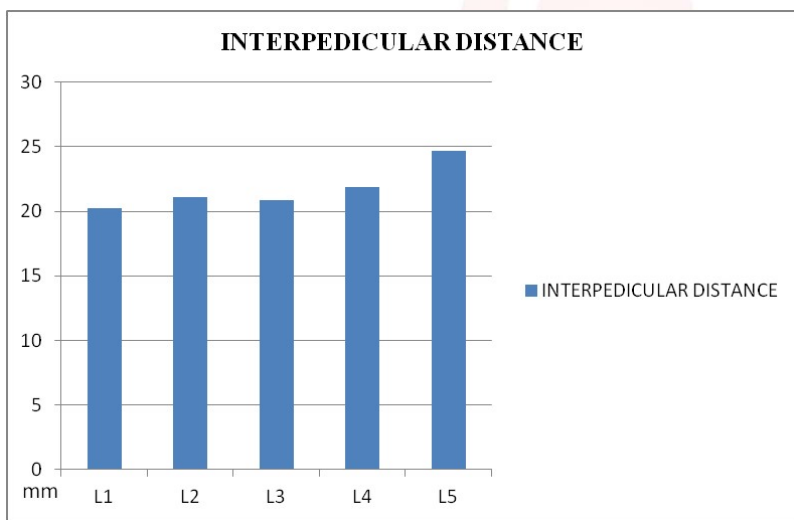

Fig. 5: Chart showing distribution of anteroposterior diameter of lateral recess at level L1-L5.

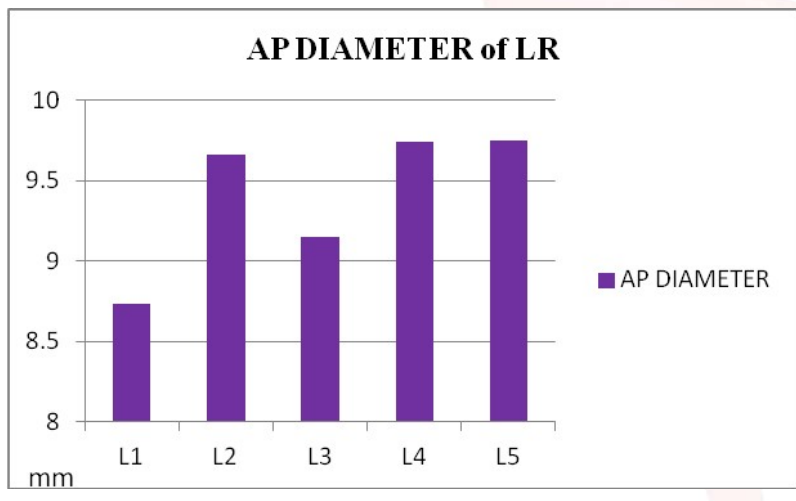

\section{DISCUSSION}

One of the most common complaints among patients worldwide is low backache and it is amongst the top musculoskeletal symptoms observed [13].

Assessment of dimensions of lumbar vertebral canal is an important tool for diagnosing low backache [12].

Normally there are regional curves when vertebral column is observed on a sagittal plane. It is made to act as shock absorber, lower down the impact and longitudinal stiffness and help in proper muscular function. The alteration of this normalcy in curve has been found to be associated with sciatica and low back pain [14]. Gradual anatomical narrowing causes lumbar spinal canal stenosis and associated clinical symptoms ranging from bilateral lower limb pain, paresthesia and low back pain $[15,16]$. Degenerative spondylolisthesis, which is often observed with lumbar stenosis, anteroposterior displacement of a vertebral body results from facet joint erosion and muscular, capsular, ligamentous attenuation, which occurs most frequently at L4-L5 and L5-S1 levels [17].

The ethnical and racial differences over different geographical areas have influences over the various lumbar canal diameters. Thus, a population specific definitive normal value is required for reference whenever we are estimating the lumbar canal stenosis and associated pathologies [18].

The best method to diagnose spinal canal stenosis is computed tomography with added myelography but plain computed tomography along with magnetic resonance imaging is also a good alternative [5]. There have been various morphometric studies done with the help of radiographs, Computed tomography and Magnetic Resonance Imaging and they comprise the majority of morphometric analysis but direct measurement from vertebrae is comparatively less [19].

A study done by Amonoo Koufi HS, however reported that direct morphometric analysis can give better and accurate as well as reproducible data [20].

In a study done by Kapoor $\mathrm{Y}$ et al, sagittal diameter ranged from 13.06-14.75 $\mathrm{mm}$ which is quite similar to my result of $13.10-14.77 \mathrm{~mm}$ at L1, L5 levels [3].

In study by Mohammed El-Rakhawy et al, Interpedicular distance ranged from 21.6-25.1 $\mathrm{mm}$, which is quite similar to my finding of 20 . 24-24.70 $\mathrm{mm}$ at L1, L5 levels [12].

Kayaoglu et al found spinal stenosis in $2.4 \%$ of their cases that required reoperation after lumbar disc surgery [21]. Stenosis in their study was noted mainly in vertebrae L4, L5 and S1, and disc pathologies and radiculopathies were 
also found there. In a study done by Tarek Aly et al on patients by Computed Tomography, it was found that narrowing occurred at L3 [22]. Similar reduction in all the diameters at L3 vertebral level was found in study done by Mohammed El-Rakhawy et al and Kapoor Y et al $[3,12]$. As per Fernando et al, study on patients by computed tomography showed that the asymptomatic group had a wider foramen from L3 to L5 than with patients with canal stenosis, which revealed lower figures for all diameters of the lumbar canal [23]. In this study, diameter increased from L1-L2 and reduction in all the diameters occurred at level L3. It again showed increase from L4-L5.

R. Spector et al in his article stated that "Cauda Equina Syndrome", maybe caused by space occupying lesions in the lumbosacral spinal canal [24]. It may lead to low back pain, sciatica, lower extremity sensorimotor loss and bowel and bladder dysfunction, reduced rectal tone. It occurs due to damage to the nerve roots forming the cauda equina and is mostly prevalent at L4-L5 or L5-S1 spinal segments. Treatment of choice is urgent surgical decompression of the spinal canal. Normal lumbar anatomy and morphometry is required to diagnose acute stenosis.

In the present study, we found that narrowing of diameter occurs at L3 level for all the measurements and we found baseline morphometric data of the lumbar vertebrae. However, in our study we did not include age, sex and ethnicity. Therefore, an extended study with more sample size over a geographical area and specific population and gender can give us data that are more informative. Comparisons with Computed tomography and Magnetic Resonance Imaging finding can also be done to find the sensitivity of those modalities in specific cases. From this study, the existence of variation and morphometric pattern can be known. This would be of extreme help to the orthopaedic surgeons, radiologists, screw and implant manufacturers. Complications after lumbar inter-body fusion, which can be done by both anterior and posterior approach, can be prevented. It will also help the physicians towards a better diagnosis and revising the rehabilitation and physiotherapy protocols.

\section{ACKNOWLEDGEMENTS}

The authors are thankful to the Department of Anatomy of Regional Institute of Medical Sciences.

\section{Conflicts of Interests: None}

\section{REFERENCES}

[1]. C Chambliss H, Roman TR, Alan SH. Lumbar Microdissection. In The Spine: Master Techniques in Orthopaedic Surgery. Edited by Thomas A Zdeblick and Todd J Albert. Lippincott Williams \& Wilkins, Philadelphia; 2014.

[2]. Standring S (2016) Gray's Anatomy: The Anatomical Basis of Clinical Practice. 41st ed. Elsevier:725-726.

[3]. Kapoor Y, Anil RS, Krishnaiah M, Suseelamma D. Morphometry of the lumbar vertebrae and its clinical significance. Sch J App Med Sci 2014; 2(2):10451052.

[4]. Jadhav AS, Katti AS, Herekar NG, Jadhav SB. Osteological study of lumbar vertebrae in Western Maharashtra population. Journal of the Anatomical Society of India 2013; 62(1):10-16.

[5]. Varol T, Iyem C, Cezayirli E, Erturk M, Kayalioglu G, Hayretdag C. Comparative morphometry of the lower lumbar vertebrae: Osteometry in dry bones and computed tomography images of patients with and without low back pain. Journal of International Medical Research 2006; 34(3):316-330.

[6]. Garfin SR, Rydevik BL, Lipson SJ. Spinal stenosis. In: Rothman Rh, Simeone FA(ed). The Spine. 3rd ed. Philadelphia: WB. Saunders;1992:791-856.

[7]. Ciricillo SF, Weinstein PR. Lumbar spinal stenosis. West J Med 1993; 171-177.

[8]. Ran B, Li Q, Yu B, Chen X, Guo K. Morphometry of lumbar spinous process via three dimensional CT reconstruction in a Chinese population. International Journal of Clinical and Experimental Medicine. $2015 ; 8(1): 1129$.

[9]. Chawla K, Sharma M, Abhaya A. Kochhar S. Morphometry of the lumbar pedicle in West India. Eur J Anat 2011; 15(3):155- 161.

[10]. Vinay KV, Beena DN, Vishal K. Lumbar pedicle morphometry in South Indians using CR-35X digitizer. Indian Journal of Fundamental and Applied Life Sciences 2012; 2(2):173-178.

[11]. Gocmen MN, Karabekir H, Ertekin T, Edizer M, Canan Y, Izzet Duyar I . Evaluation of lumbar vertebral body and disc: a stereological morphometric study. Int. J. Morphol 2010; 28: 841-847.

[12]. El Rakhawy M, Abd El Rahman ES, Ibrahim L, Ehab A. Lumbar vertebral canal stenosis: concept of morphometric and radiometric study of the human lumbar vertebral canal. International Journal of Experimental and Clinical Anatomy of the Human Lumbar Vertebral Canal 2010; 4: 51- 62.

[13]. Atta Alla El SS, Saab IM, El Shishtawy M, Hassan KH. Morphometric study of the lumbosacral spine and some of its related angles in Lebanese adult females. Ital J Anat Embryol 2014; 119(2): 92-105. 
[14]. Kim HJ, Chung S, Kim S. Influences of trunk muscles on lumbar lordosis and sacral angles. Eur Spine J 2006; 15: 409-414.

[15]. Storm PB, Chou D, Tamargo RJ. Lumbar spinal stenosis, cauda equina syndrome, and multiple lumbosacral radiculopathies. Phys Med Rehabil Clin N Am 2002; 13(3):713- 733.

[16]. Bajwa NS, Toy JO, Ahn NU. Application of a correlation between the lumbar Torg ratio and the area of the spinal canal to predict lumbar stenosis: a study of 420 postmortem subjects. J Orthop Traumatol 2013; 14(3):207-212.

[17]. Fraser JF, Huang RC, Girardi FP, Cammisa FP JR. Pathogenesis, presentation and treatment of lumbar spinal stenosis associated with coronal (or) sagittal spinal deformities. Neurosurg Focus 2003; 14(1):e6.

[18]. Kamble YS, Kulkarni PR, Joshi UU. Morphometry and sexual dimorphism of lumbar pedicles in dry bones of Maharashtra region. Int J Anat Res 2017; (4.3):4654-4659

[19]. Azu OO, Komolafe OA, Ofusori DA, Ajayi SA, Naidu ECS, Abiodun AA, Naidu E. Morphometric study of lumbar vertebrae in adult South African subjects. Int. J. Morphol 2016; 34(4):1345-1351.
[20]. Amonoo-Kuofi H. Maximum and minimum lumbar interpedicular distances in normal adult Nigerians. Journal of Anatomy 1982; 135 (Pt 2): 225.

[21]. Kayaoglu CR, Calikoðlu C, Binler S. Re-operation after lumbar disc surgery: results in 85 cases. Journal of International Medical Research 2003; 31(4):318-323.

[22]. Aly T, Amin O. Geometrical dimensions and morphological study of the lumbar spinal canal in the normal Egyptian population. Orthopedics. $2013 \mathrm{Feb}$ 1; 36(2):e229-34.

[23]. Santiago F, Milena G, Herrera R, Romero P, Plazas P. Morphometry of the lower lumbar vertebrae in patients with and without low back pain. European Spine Journal 2001; 10(3): 228-233.

[24]. Spector LR, Madigan L, Rhyne A, Darden B II, Kim D. Cauda Equina Syndrome. Journal of American Academy of Orthopaedic Surgeons 2008; 16(8): 471-479.

\section{How to cite this article:}

Suranjana Banik, Ajita Rajkumari. MORPHOMETRIC ANALYSIS OF LUMBAR VERTEBRAE AND ITS APPLIED CLINICAL IMPORTANCE. Int J Anat Res 2019;7(2.1):6381-6386. DOI: 10.16965/ijar.2019.122 